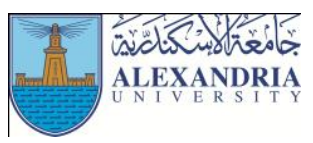

\title{
Effect of Teaching-Games-For-Understanding (TGfU) Approach on High School Students' Basketball Performance
}

\author{
Bruce Nkala $^{1}$, Jimoh Shehu ${ }^{1}$ \\ ${ }^{1}$ Physical Education Department, University of Botswana
}

\begin{abstract}
The purpose of this study was to compare the effect of the Teaching Games for Understanding (TGfU) approach on basketball performance of 35 (14-16year old) students. Five components were used to test performance namely, decision making, skill execution, support, cover and guarding. The combination of these components was used to calculate overall game performance. Participants were separated into two groups namely the Traditional (Control) group and the TGfU (Experimental) group. Pre and post-tests data were video recorded for both groups. A mean difference comparison of the GPAI components showed that the TGfU group performed better that the Traditional group. However, this difference was not significant in four of the five GPAI components, only showing significance in the cover at alpha level 0.05. The results also showed that the TGfU group performed significantly better in overall game performance than the Traditional group.
\end{abstract}

\section{Introduction}

$\mathrm{R}$ esearch in physical education has revealed two main approaches to teaching of games - the traditional/technical approach and the tactical/games approach (Allison \& Thorpe, 1997; Bunker \& Thorpe, 1982; Butler \& McCahan, 2005; Mitchell, Oslin, \& Griffin, 2006; Butler, 2006). The traditional/technical approach is a teacher-centred approach "based on the behaviourist learning theory, which advocates for the use of direct instruction by teachers, who are the "keepers of knowledge" who "transmit" information to "receptive" students (Butler \& McCahan, 2005). It is an approach designed around of skill practice followed by feedback from the teachers before resuming or proceeding to another round of skill repetition (Light, 2003). This repetition of sports skills being taught in isolation and later incorporated into game situations (Harrison, Preece, Blakemore, Richards, Wilkinson, \& Fellingham, 1999) is believed to advance the learner towards mastery. Indeed, many PE teachers belief that learners cannot play a game without the necessary background skill first (Mitchell, Oslin, \& Griffin, 2006). However, games' teaching under the traditional approach is often boring, leading to high dropout rates and little or no tactical understanding (Mitchell, Oslin, \& Griffin, 2006; Butler \& McCahan, 2005; Butler, 2006). Conversely, the games approach is based upon constructivist learning theory, which enables the learner to individually or within a group solve critical problems; thus promoting ownership of the learning process and relatively permanent knowledge of the activity (Butler, Oslin, Mitchell, \& Griffin, 2008). This approach focuses on the learner and their ability to understanding of game play (Richard \& Williams, 2005). The game is usually a modified version of the real game. This is then followed by skills practice in a full original game situation. The ownership of the learning process developed by the learner makes Teaching Games for Understanding (TGfU), both a learner-and game centred approach (Griffin \& Patton, 2005). Unlike the traditional approach, the tactical approach begins with tactical awareness of the game, followed by technical skills execution. Tactical awareness leads to more meaningful learning for learners as they enter into practice situations to develop technical skills (Hopper, 1998).

Through conferences and workshops designed to enhance its use, TGfU has become a focus of instruction in various countries and a major part of curricula in places like Australia, Singapore and Canada. However, it has been adopted with modifications to suit particular contexts. Modifications of TGfU include: Games Sense in Australia, which has been modified for coaching; Play Practice also in Australia, which is specifically aimed at encouraging beginners; Tactical games models in the USA which collapsed the 6-step model into three to provide easy access for practitioners; the Games Concept Approach in Singapore modelled after Game sense; and the Invasion 
Games Competence Model in Europe (Belgium, Portugal, Netherlands, Czech Republic), which deals with the competence of players in the modified invasion games together with emphasis on off the ball actions (Butler, Oslin, Mitchell, \& Griffin, 2008). Comparisons of the traditional approach and the TGfU approach have been conducted since the proposal of the TGfU model in 1982. Most of the comparisons have been shaped around: (a) game performance, (b) skill development, and (c) player enjoyment with the purpose of assessing the relative strengths and weaknesses of each approach. McPherson (1991, 1992) and McPherson and French (1991) studied Tennis among 6th grade, while Gadriele and Maxwell (1992) studied squash both amongst college students. Turner and Marinek (1992, 1995) studied 6th and 7th grade Field Hockey. Mitchell, Griffin and Oslin (1995) studied both Volleyball and Soccer amongst 6th grade students. 1996, saw two major studies conducted, the first by French, Taylor Hussey and Jones (1996); the other by French, Werner, Rink, Taylor and Hussey (1996). Allison and Thorpe (1997) followed with a comparison of the effectiveness of two approaches in 1997. Rovegno, Nevett, Brock and Babiarz (2001) presented a series of articles pertaining to the Learning and Teaching of Invasion Game Tactics in Fourth Grade. This series featured studies of varying duration within the game category and represents the pedagogical studies comparing TGfU and the technical approach.

Initial research pertaining to the development of skill indicated no significant differences between the tactical and technical approaches with relation to skill development (French, Warner, Rink, Taylor, \& Hussey, 1996). Turner \& Martinek (1992, 1995) investigated the differences in the two approaches in Field Hockey using 6 th and 7 th grade students. None of the approaches resulted in skill difference over a 6-class period (Turner \& Martinek, 1992). Subsequent study in 1995 increased the period of research to 15 classes. This study showed a difference in the skill group with relation to accuracy and time, but no difference in the experimental group (Turner \& Martinek, 1992). Griffin, Mitchell, \& Oslin (1995, 1995), also both reported no difference over the research period of 9 and 8 sixth grade classes of Volleyball and Soccer, respectively. However, McPherson (1991, 1992) and McPherson \& French (1991), conducted research on college students over a semester. The population was randomly separated into two groups namely; a skill group and strategy group which was not given instruction of skill. Of the two research groups, the skill group (technical model) showed improvement, but the strategy group did not improve until they switched to the skill section of the research. Allison and Thorpe (1997) provided the first evidence of skill development recorded in a tactical approach group. Using two groups, 40 boys and 56 girls, the authors randomly assigned them to tactical and technical sub-groups. The girls played hockey while the boys played basketball for a 12-week period. Each group received a $6 \times 1$ hour weekly teaching session, resulting in a total of 72 contact hours. The increased duration of study produced a significant difference. Other shorter duration studies have not produced any significant difference in skill development in Tactical Approach groups.

With regards to cognition, Turner and Martinek (1992) found no difference in both procedural and declarative knowledge. However, over a longer period of study, Turner and Martinek (1995) found that the procedural knowledge was better within the tactical group, but no difference was observed pertaining to declarative knowledge within both groups. However, Nevett, Rovegno, Babiarz and McCaughtry (2001) concluded that during a 12-weeks session of teaching and learning cutting and passing tactics using both approaches, 4th graders were able to improve their passing decisions and cutting actions by $66.6 \%$ and $64.1 \%$ respectively (Nevett, Rovegno, \& Babiarz, 2001; Nevett, Rovegno, Babiarz, \& McCaughtry, 2001). French, Werner, Taylor, Hussey and Jones (1996) during their 6-week comparative study of a Ninth-Grade Badminton class, concluded that of the three groups namely; the tactical, skill (technical) and combined (TGfU), the skill and combined groups showed the highest levels of cognitive understanding. Similar conclusions were arrived at by Allison and Thorpe (1997), that the "tests show a significantly greater increase in knowledge and tactical understanding during the games for understanding lesson" (Allison \& Thorpe, 1997). This was also confirmed in the volleyball study of 6th grade students by Griffin, Mitchell, \& Oslin (1995) particularly stating that the tactical group showed a greater understanding of tactical knowledge, even though both groups showed no in-between difference in skill related improvement. McPherson $(1991,1992)$ and McPerson French (1991) in their study using college tennis students showed the both groups improved, concluding that knowledge development occurs concurrently with skill development. This improvement in both approaches was also found in the study of collegiate female soccer players. Haneshi, Griffin, Siegel, \& Shelton, (2008) reported that the tactical approach "produced positive effects on improving game performance, although it was not statistically significant to conclude that one approach was better than the other (Haneshi, Griffin, Siegel, \& Shelton, 2008).

\section{Theoretical Framework}


Teaching Games for Understanding, the crux of this study, is based on constructivism, a learning theory anchored on decades of cognitive development research (Piaget, 1995; Bruner, 1996; Vygotsky, 1978). Constructivism emphasizes reflection, meaning making, shared inquiry, situated activity and knowledge building in light of previous experience as against the use of stimulus/response (behaviourist) approach to altering behavior (Schunk, 2014; Glaserfeld, 1995). Constructivist learning entails activity rather than passivity, diversity rather than fixity, flexibility rather than rigidity, and creativity rather than conformity. The constructivist approach enables the learner to engage with, and interpret, new ideas using prior knowledge and experience as frames of reference under the guidance of the teacher or in collaboration with classmates. A key element of constructivism is problem-solving, involving metacognition, hypothesis testing, knowledge discovery and application, and adjustment of knowledge construction in light of situational outcomes. The role of the teacher in this context is to enable students figure out the necessary learning principles by themselves through provision of relevant activities, Socratic dialogue to determine preconceived notions, non-judgmental questioning to reveal errors in current suppositions, opportunities for knowledge applications in real situations, and encouragement of reflection to enlarge learners' cognitive abilities (Bruner, 1990; Ertmer \& Newby, 1993; Driscoll, 2005; Fosnot, 2005).

As an offshoot of constructivism, the TGfU approach is student-centred, concept-driven and participatory. It is predicated on helping learners make sense of games through appropriate tasks that encourage shared exploration, analysis, guided discovery, strategic thinking and tactical awareness needed to make informed decisions about skill development and deployment The approach prioritizes the enhancement of cognitive processes and game re-conceptualization. The focus is on student learning beyond the information provided with the PE teacher serving as a facilitator rather than a lecturer or transmitter of knowledge. Thus, constructivists PE teachers provide their students with ample opportunities to think conceptually, participate meaningfully in the learning process and identify important principles for solving tactical problems in a variety of games situations (Griffin, Brooker \& Patton 2005).

\section{Purpose of Study}

The Botswana Junior Certificate Physical Education curriculum was revised in 2009. A key outcome of this review is the shift towards the use of TGfU to enhance students' conceptual understanding in Physical Education and improve tactical intelligence, confidence and competence in sports-related Physical Education (MOESD, 2008). After the initial roll-out of the new curriculum, an evaluation was conducted by Department of Curriculum Development and Evaluation six months later. Two main challenges were found regarding the instructional model: the first being teachers' unwillingness to change, the other being their inability to implement it due to limited knowledge (Caiphas, 2011). Convincing educators who are well grounded in the traditional teaching approach to adopt a new instructional approach must begin with establishing tangible, "strong empirical data that would support our intuitive sense that this approach works for students" (Butler, Oslin, Mitchell, \& Griffin, 2008, p. 10). As such, this study was conducted to provide contextualised evidence of the effect of the TGfU model in a Botswana school context.

\section{Materials \& Methods}

This was a quasi-experimental study using the nonequivalent control group design approach. Though the individuals are not randomly assigned, the intact groups were randomly assigned to control and experimental groups. Besides, both groups underwent a pre-test and post-tests, with only the experimental group receiving treatment during the study. The research was conducted in a private school in the capital city of Botswana; with a population of 640 co-ed students from diverse backgrounds. Physical education is compulsory for the entire lower school with each class timetabled for 2 hours of lessons on a six day cycle timetable. Each lesson is 50 minutes and is generally divided into 10 minutes at the beginning and end of the lesson for changing, thus leaving 30 minutes per lesson for instruction. Classes are assigned to streams namely J, K, L and M. For physical education classes, two streams attend at the same time. For instance, $\mathrm{J}$ will be combined with $\mathrm{K}$, while $\mathrm{L}$ is combined with $\mathrm{M}$ to form one physical education class. The classes are separated by gender between two full-time physical education instructors, assisted by two teacher assistants each.

The study population consisted of 110 Form 2 students. A sample of 43 students volunteered to take part in the study, but only 35 completed the study by conforming to all the study regulations. Of these students, 26 were male and 9 were female, which translates to $74 \%$ male and $26 \%$ female. The participants were divided into two groups namely the Traditional (control) group and the Teaching Games for Understanding (TGfU) group. The traditional group consisted of 16 (46\%) subjects while the TGfU group had 19 (54\%) subjects. Participants were assigned identity numbers that were worn during Pre/Post testing. 
Each team comprised high, medium and low skilled players. As in previous studies, this allowed for equal matchups on defence and ensures success for the less able students within the same ability level (Rovegno, Nevett, Brock, \& Babiarz, 2001).

The Games Performance Assessment Instrument (GPAI) by Oslin, Mitchell, \& Griffin (1998) was used for data collection. The instrument contains seven basic components that apply across all the categories of play. The first five components, for example, apply to striking/fielding games and while the bottom five in Table 1, applies to invasion games (Oslin, 2005; Oslin, Mitchell, \& Griffin, 1998; Griffin, Mitchell, \& Oslin, 1995; Mitchell, Oslin, \& Griffin, 2006).

Table (1)

GPAI Components of Invasion Game Play - adapted from (Oslin, 2005)

\begin{tabular}{|c|c|}
\hline Components & Definition \\
\hline Decisions Making & Making appropriate choices about what to do with the ball (or object) during the game \\
\hline Skill Execution & Efficient performance of selected skills \\
\hline Support & Off-the-ball movement to a position to receive a pass (or throw) \\
\hline Cover & Defensive support for players making a play on the ball, or moving to the ball (or object) \\
\hline Guard & Defending an opponent who may or may not have the ball (or object) \\
\hline
\end{tabular}

As recommended by Oslin, Mitchell, \& Griffin (1998), a 1-5 rating scale is best for scoring invasion games, rather than the traditional tally mark system. This rating score was used to indicate the level of frequency of performing an action in the components of decision-making, skill execution, support, guarding and cover components. The criteria for each component assisted the coders to understand the expectations of the components, which provided a standard for other coders. Each criterion was scored using the 1-5 rating scale, with 5 indicating the demonstration of a criterion and 1 indicating failure to demonstrate the criterion. The mean score of the all the criteria within a component was used to represent the component score (see Table 3). After assessing each component using the GPAI, scores were computed. The Overall Game Performance was taken as the average of the components scores which was expressed as a percentage. The closer it is towards $100 \%$, the better the performance of the individual (Mitchell, Oslin, \& Griffin, 2006; Oslin, 2005).

The wide use of the GPAI as an assessment tool for games is justification enough of its validity. This is supported by Oslin, Mitchell, \& Griffin's (1998) study titled The Game Performance Assessment Instrument (GPAI): Development and Preliminary Validation, which concluded that the GPAI has high face validity. Of the 18 sophomore-level class participants, $95 \%$ responded positively to the being assessed during game play using the GPAI - stating that "it did not feel like a test" (Oslin, Mitchell, \& Griffin, 1998). Construct validity was measured by the GPAI's success to distinguish between high and low game performance ability (Oslin, Mitchell, \& Griffin, 1998). In three separate middle school studies of Basketball, Soccer and Volleyball, a physical education specialist was asked a priori to categorize students' game play performance as low medium and high. Only the low and high students were used for the study and underwent a 5-minute pre-test game which was videotaped. After analysis of the videotaped session and assessment using the GPAI and statistical t-test, it was determined that the GPAI had an effect-size (ES) of greater than 1.0 in six of the nine ES's, which according to Thomas and Nelson (1996) is classified as large (Oslin, Mitchell, \& Griffin, 1998); meaning that the GPAI has a large construct validity rating.

Block plan lessons and individual lessons were designed to teach students in both groups not only the basic skills of basketball passing, dribbling, shooting, but also a basic offensive and defensive plays'. A typical physical education lessons took the following format: 10-minutes at the beginning of the lesson to change and come to the court; 10-minutes warm-up and passive stretch; 25minutes instruction/game practice; 5-minutes to change for the next class. The high allocation of changing time was due to the location of the changing rooms in relation to the basketball courts, but also that the students were coming from different classes before physical education. For the Control group, the 25-minutes of instructional time were used to provide skill instruction, and finishing with a game. Feedback during the game was restricted to skill cues rather than tactical play. For the Experimental group however, the 25-minutes of instructional time began with a modified game designed to teach the specific tactical component of the lesson. After guided questioning and when the students understood the skill/s needed for the game, the students was asked to practice the relevant skills before being given another opportunity to play another modified game. Feedback for this group was in the form of skill and tactical cues.

The five game components that apply to invasion games are shown in Table 2. During the pre- and post-tests, 
students participated in a 5-minute 3 vs 3 half-court basketball game which was video-recorded using two video tape recorders: a Sony DCR-HC28E Handycam digital video camera and a Panasonic 3CCD 2,3Mega pixels. Both were mounted on a tripod and set to wide view. The unedited video footage was transferred to TDK DVD-R 120mins/4.7GB disc. Oslin, Mitchell, \& Griffin's (1998) GPAI data sheet was used by all parties during assessment. For the observations to be valid, the coders needed to establish an inter-observer agreement coefficient of greater than $80 \%$ using Kendall's W Coefficient on concordance (Oslin, Mitchell, \& Griffin, 1998). However, because of the large amount of video recording, Haneshi, Griffin, Siegel, \& Shelton, (2008) suggest that the assessment of the inter-observer agreement be run on only $30 \%$ of the videos (Haneshi, Griffin, Siegel, \& Shelton, 2008). As such, inter-observer reliability between three coders in this study was established using data for 6 students. The reliability coefficient was established using
Kendall's W Coefficient on Concordance. A .86 agreement was obtained between the coders. A series of analysis of variance (ANOVA) were conducted to test for significant differences (at .05 alpha level) in scores between the traditional group and the TGfU group according to the GPAI components.

\section{Results}

An assessment of the GPAI component mean scores revealed that participants in the TGfU group displayed a greater increase in all the GPAI components scores as compared to the mean of the traditional group. The highest difference between the means was observed in the cover component where the TGfU group improved their mean score by .82 while the traditional group only managed a .25 increase in mean scores. The TGfU group improved their support scores by .98 which was 2.65 times more than the traditional group in this component.

Figure (1)

Scores of Mean GPAI Component Difference

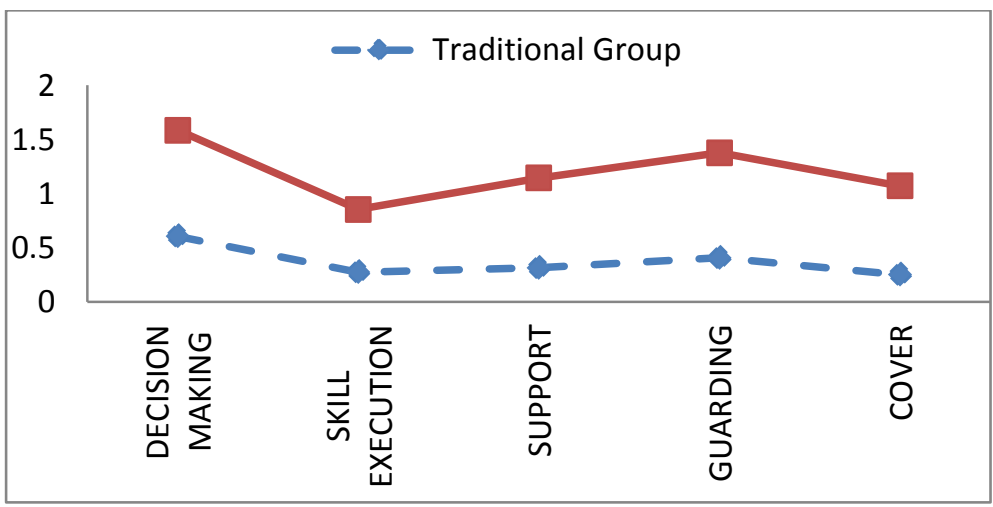

The mean difference of .97 in guarding was 2.3 times higher compared to the traditional group which managed a .406 mean difference. Skill execution amongst the TGfU group was 2.1 times better at .58 compared to the .273 mean difference score of the traditional group. In decision making, the TGfU group scores a mean difference of .98 while the traditional group had a mean score of .604.At 16.6 mean differences the TGfU group had a 2.24 times better overall game performance than the 7.4 mean difference displayed by the traditional group. Table 2 shows a summary of the descriptive statistics explained above. The GPAI data were tested further using one way ANOVA. What follows is a presentation of the results of the statistical tests derived using SPSS for windows version 16.0. Table 2 shows the GPAI component results. 
Table (2)

Mean GPAI Component Scores

\begin{tabular}{|c|c|c|c|c|c|c|c|c|c|c|c|c|}
\hline & \multicolumn{10}{|c|}{ GPAI components } & \multirow{2}{*}{\multicolumn{2}{|c|}{$\begin{array}{l}\text { Overall game } \\
\text { performance }\end{array}$}} \\
\hline & \multicolumn{2}{|c|}{$\begin{array}{c}\text { Decision } \\
\text { making }\end{array}$} & \multicolumn{2}{|c|}{ Skill execution } & \multicolumn{2}{|c|}{ Support } & \multicolumn{2}{|c|}{ Guarding } & \multicolumn{2}{|c|}{ Cover } & & \\
\hline & $\mathrm{X}$ & SD & $X$ & SD & $\mathrm{X}$ & SD & $\mathrm{X}$ & SD & $X$ & SD & $X$ & SD \\
\hline Traditional Pre test & 2.85 & .852 & 2.54 & .612 & 2.13 & .556 & 1.91 & .779 & 2.23 & .841 & 46.6 & 12.1 \\
\hline Traditional Post test & 3.46 & .824 & 2.81 & .661 & 2.44 & .291 & 2.31 & .854 & 2.48 & .516 & 54.0 & 9.4 \\
\hline Mean difference & \multicolumn{2}{|c|}{0.604} & \multicolumn{2}{|c|}{0.273} & \multicolumn{2}{|c|}{0.313} & \multicolumn{2}{|c|}{0.406} & \multicolumn{2}{|c|}{0.250} & \multicolumn{2}{|c|}{7.4} \\
\hline TGfU Pre test & 2.86 & .911 & 2.52 & .654 & 1.98 & .481 & 1.93 & .786 & 2.27 & $\begin{array}{c}.70 \\
8\end{array}$ & 46.3 & 11.6 \\
\hline TGfU Post test & 3.84 & .804 & 3.10 & .714 & 2.81 & .570 & 2.90 & .542 & 3.09 & $\begin{array}{c}, 58 \\
6\end{array}$ & 62.9 & 10.45 \\
\hline Mean difference & \multicolumn{2}{|c|}{0.98} & \multicolumn{2}{|c|}{0.58} & \multicolumn{2}{|c|}{0.83} & \multicolumn{2}{|c|}{0.97} & \multicolumn{2}{|c|}{0.82} & \multicolumn{2}{|c|}{16.6} \\
\hline
\end{tabular}

Decision making: The hypothesis pertaining to decision making was tested and no significant difference between the two groups was detected $\mathrm{F}(1,34)=.314, \mathrm{p}>.05$. Therefore the null hypothesis that there is no significant difference between the two groups with reference to decision making was retained.

Skill execution: Concerning skill execution, the results of the ANOVA was not significant $(\mathrm{F}(1,34)=.073, \mathrm{p}>.05)$.
Therefore, the null hypothesis that there is no significant difference between the two groups in skill execution was retained.

Support: The null hypothesis of no significant difference between the two groups in the ability to provide support was also retained. $(\mathrm{F}(1,34)=3.652, \mathrm{p}>.05)$.

Table (3)

Analysis of Variance on GPAI Components

\begin{tabular}{|c|c|c|c|c|}
\hline GPAI Components & $\mathrm{df}$ & Mean Square & $\mathrm{F}$ & Sig. \\
\hline \multirow[t]{3}{*}{ Decision making score } & 1 & .166 & .314 & .579 \\
\hline & 33 & .528 & & \\
\hline & 34 & & & \\
\hline \multirow[t]{3}{*}{ Skill execution score } & 1 & .064 & .073 & .789 \\
\hline & 33 & .876 & & \\
\hline & 34 & & & \\
\hline \multirow[t]{3}{*}{ Support score } & 1 & 2.978 & 3.652 & .065 \\
\hline & 33 & .815 & & \\
\hline & 34 & & & \\
\hline \multirow[t]{3}{*}{ Guarding score } & 1 & .695 & 1.607 & .214 \\
\hline & 33 & .433 & & \\
\hline & 34 & & & \\
\hline \multirow[t]{3}{*}{ Cover score } & 1 & 2.748 & 9.126 & $.005^{*}$ \\
\hline & 33 & .301 & & \\
\hline & 34 & & & \\
\hline
\end{tabular}

$* \mathrm{p}<.05$

Guarding: Similarly, no significant difference was found between the ability of both groups to guard $(\mathrm{F}(1,34)=$ $1.607, \mathrm{p}>.05)$.

Cover: However, significant difference was found with respect to the ability to provide cover for a teammate ( $\mathrm{F}$
$(1,34)=9.126, p<.05)$. Thus the null hypothesis that there is no significant difference between the two groups with regards to the ability to provide cover was rejected.

\section{Game Performance:}


One-way ANOVA was used to test for significance a between the traditional and the TGfU groups with respect to overall game performance. No significance was found in the pre-test game performance $\mathrm{F}(1,34)=.009, \mathrm{p}>.05$. However, significance was found in the overall post test scores with $\mathrm{F}(1,34)=7.109, \mathrm{p}<.05$. See Table 4

Table (4)

Analysis of Variance on Overall Game Performance

\begin{tabular}{|l|c|c|c|c|}
\hline & df & Mean Square & F & .009 \\
\hline \multirow{2}{*}{ Pre-test Overall Performance } & 1 & .000 & & \\
\cline { 2 - 5 } & 33 & .013 & & \\
\cline { 2 - 5 } & 34 & & 7.109 & $.012 *$ \\
\hline Post-test Overall Performance & 1 & .071 & & \\
\cline { 2 - 5 } & 33 & .010 & & \\
\hline
\end{tabular}

$* \mathrm{p}<.05$

\section{Discussion}

The findings of this study revealed that both groups improved their GPAI component scores in the 10 weeks of basketball. The TGfU groups obtained 2.65 time higher scores than the traditional group scores, confirming what was observed by Harvey (2003) in his study of U19 college soccer players where similarly high percentage rises in scores were observed between the two groups. Harvey (2003) observed a rise in the TGfU group GPAI component and index scores. Similarly, Nevett, Rovegno, Babiarz and McCaughtry (2001) concluded that during a 12-weeks session of teaching and learning cutting and passing tactics using both approaches, 4th graders were able to improve their passing decisions and cutting actions by $66.6 \%$ in the TGfU group, higher than the $64.1 \%$ of the technical group (Nevett, Rovegno, \& Babiarz, 2001; Nevett, Rovegno, Babiarz, \& McCaughtry, 2001). Though the present study indicated a higher rise in TGfU mean scores, these figures were not significant enough to reject the null hypothesis. Similar findings were observed by Haneshi, Griffin, Siegel, \& Shelton, (2008) in a study of collegiate female soccer players that investigated three components included in the present study namely, decision making, cover and skill execution. Haneshi, Griffin, Siegel and Shelton (2008), indicated that though no significance was observed between the two group scales, "seemingly the games approach produced positive effects in improving game performance" (Haneshi, Griffin, Siegel, \& Shelton, 2008).

One of the main arguments against Games for Understanding approach discussed by Allison \& Thorpe (1997) is the supposed detrimental effect it is thought to have on the development of technical skill (Allison \& Thorpe, 1997). Though a rise in the mean score was observed, no statistical significant difference was recorded between the groups in skill execution. Similar studies reported no significant difference between the groups' skill related improvement. McPherson $(1991,1992)$ and McPerson French (1991) in their study of college tennis students reported that both groups improved, concluding that knowledge development occurs concurrently with skill development. However, no significant differences were observed between the tactical and technical approaches with relation to skill development (French, Warner, Rink, Taylor, \& Hussey, 1996). Turner \& Martinek (1992, 1995) investigated the differences between the two approaches in Field Hockey involving 6th and 7 th grade students, and reported that none of the approaches resulted in skill difference over a 6-class period. Even in a subsequent study in 1995, where Turner \& Martinek increased the period of research to 15 classes using the same population, no difference in the experimental group was found (Turner \& Martinek, 1992). Griffin, Mitchell, \& Oslin $(1995,1995)$ also reported no difference over the research period between 9 and 8 sixth grade classes of Volleyball and Soccer, respectively. Similarly, the study by McPherson (1991, 1992) and McPherson \& French (1991), on college students showed that the strategy group (tactical) did not improve until they switched to the skill section of the research.

Nevertheless, Allison and Thorpe (1997) found significant difference in skill execution in their comparative study of these two teaching approaches. At the end of a 12-week period, significant skill development was recorded between the two groups.

In this study significance in overall game performance was found when the traditional approach to teaching was compared to the TGfU approach. This confirms previous 
comparative research studies that also indicated significant differences in the performance of TGfU subjects as compared to the traditional or control groups (Harvey, 2003; French, Warner, Rink, Taylor, \& Hussey, 1996; Allison \& Thorpe, 1997; Nevett, Rovegno, Babiarz, \& McCaughtry, 2001; Nevett, Rovegno, \& Babiarz, 2001). This was also confirmed in a more recent comparative study by Haneshi, Griffin, Siegel, \& Shelton, (2008), where soccer players "performed better in overall game performance" (Haneshi, Griffin, Siegel, \& Shelton, 2008) after eight weeks of practicing. However, Haneshi, Griffin, Siegel, \& Shelton, (2008) reported that the tactical approach though produced positive effects on improving game performance, "it was not statistically significant" (Haneshi, Griffin, Siegel, \& Shelton, 2008).

Contrary to Haneshi, Griffin, Siegel, \& Shelton, (2008), Allison and Thorpe's (1997) finding indicated a significant increase in knowledge and tactical understanding (Allison \& Thorpe, 1997). Knowledge understanding in this particular study indicated the ability to make appropriate decisions of when to pass/dribble/shoot (Allison \& Thorpe, 1997). In the present study, this was tested under the decision making component. Allison and Thorpe (1997) also believed that the decision making "related to execution of skill" in particular positioning of teammates and/or opposition time and space availability (Allison \& Thorpe, 1997). These were referred to under tactical in Allison and Thorpe (1997) study and similar criteria are found in the present study under skill execution support, guarding and cover components - collectively expressed in percentage, as game performance. Therefore, the significance in overall game performance found in this study is supported by the findings of Allison and Thorpe (1997) regarding knowledge and tactical understanding. Further support for the findings of the present study with regards to overall game performance can also be found in Griffin, Mitchell, \& Oslin's (1995) volleyball study of 6th grade students which stated that the tactical group showed a greater understanding of tactical (what to do, when to do it) knowledge (Griffin, Mitchell, \& Oslin, 1995). Other previous studies also indicate that the overall game performance improved in the Tactical (TGfU) group more than the traditional group. This is also seem in (Harvey, 2003; Nevett, Rovegno, \& Babiarz, 2001; Nevett, Rovegno, Babiarz, \& McCaughtry, 2001)

\section{Implications of Findings for Basketball Teaching and Performance Improvement}

To enhance students' tactical intelligence and performance in basketball (that is, deep games thinking and meaningful games playing), it is important from the constructivist/TGfU perspective to:

Use students' prior perceptions, beliefs and experiences as a basis for contextualizing and constructing new knowledge

Differentiate instruction in light of learners' individual differences

Use questioning and reflections to enable students see how individual tactical elements (parts) are connected to the overall game strategy (whole)

Guide the knowledge discovery process through reasoned performance analysis and Socratic dialog

Encourage multiple solutions to a given tactical challenge to promote divergent thinking, innovation and tactically savvy players Emphasize conceptual understanding rather than mere reproduction of abstracted techniques

Teach skills within the context of games tactics and strategy

Promote peer discourse, collaboration and knowledge sharing to engender self-directed, emergent and adaptive learning

Provide pertinent activities to enable students test their ideas, develop competencies and apply concepts appropriately

Use formative assessments to produce long-term cognitive development outcomes; and

(10) Respect students' tactical perspectives and use those perspectives to assess conceptual understanding and improve performance.

\section{Conclusion}

Overall, the TGfU approach improves basketball performance amongst Form 2 students over 10 lessons, especially in girls. The higher mean differences between pre/post scores that were observed in the TGfU group as compared to the traditional group, implies that TGfU can improve performance across the invasion game GPAI components. Though the results indicated that the TGfU group significantly improved students' overall performance and ability to provide cover, it did not result in significant performance difference in the four other components - Decisions Making, Skill execution, Support, and Guard. The lack of significant difference in decision making could have been due to the restrictive three pass rule that was designed to ensure that everyone had a chance to touch the ball. Though participants made the appropriate decision to pass the ball rather than shoot, 
passes were often made to a guarded individual. This may have contributed to the low number of passes that reached the target; as such, affecting skill execution. Future studies should be conducted under normal basketball game environment. Significant difference was also not observed in the ability to provide support. Only 2 of the 35 students who took part in this study attempted to free a teammate, but an increased ability to move into open spaces was demonstrated by the TGfU group. This may have contributed to the high scores in the support component.

This study used the quasi-experimental non-equivalent control group approach, with attendant threats to internal validity. Accordingly, a true experimental research study should be conducted in the future. The current study was also limited to one population in one school. Therefore, a replication of this study across different school populations is recommended. The length of the study did not represent the normal length of a physical education module. As such, future research is needed to ascertain the effect of the TGfU approach on performance over a longer period in order to identify the exact time of significant change in performance. Future studies should also be conducted to identify the psychological impact of the TGfU approach on participants especially in the African context.

\section{References}

1- Allison, S., \& Thorpe, R. (1997). A Comparison of the Effectiveness of Two Approaches to Teaching Games within Physical Education. A Skills Approach versus a Games for Understanding Approach. British Journal of Physical Education, 28 (3), 9-13.

2- Blompvist, M. T., Luhtanen, P., Laakso, L., \& Keskinen, E. (2000). Validaton of a Video-Based GamesUnderstanding Test Procedure in Badminton. Journal of Teaching Physical Education, 19, 325-337.

3- Brooks, M. G. \& Brooks, J. G. (1999). The Courage to Be Constructivist. The Constructivist Classroom, 57(3):18-24.

4- Bruner, J. (1990). Acts of Meaning. Cambridge, MA: Harvard University Press.

5- Bruner, J. (1996). The Culture of Education. Cambridge, MA: Harvard University Press.

6- Bunker, D., \& Thorpe, R. (1982). A Model for Teaching of Games in Secondary School. Bulletin of Physical Education, 18, 7-10.

7- Bunker, D., \& Thorpe, R. (1986). From theory to practice. In R. Thorpe, D. Bunker, \& L. Almond,
Rethinking Games Teaching (pp. 11-16). Loughborough: Loughborough University of Technology.

8- Butler, J. (2006). Curriculum Constructions Of Ability : Enhancing Learning Through Teaching Games for Understanding (TGfU) As A Curriculum Model. Sport, Education and Society, 11(3), 243-258.

9- Butler, J. (1997). How Would Socrates Teach Games? A Constructivist Approach. Journal of Physical Education, Recreation and Dance, 68 (9), 42-47.

10- Butler, J., \& McCahan, B. (2005). Teaching Games for Understanding As A Curriculum Model. In L. Griffin, \& J. Butler, Teaching Games for Understanding: Theory, Research, and Practice (pp. 33-54). USA: Human Kinetics.

11- Butler, J., Oslin, J., Mitchell, S., \& Griffin, L. (2008). The Way Forward for TGfU: Filling the Chasm between Theory and Practice. Physical \& Health Education Journal, 74 (2), 6-12.

12- Caiphas. (2011, August 18). (M. B. Nkala, Interviewer) Gaborone, Botswana.

13- Darst, P. W., Zakrajsek, D. B., \& Mancini, V. H. (1989). Analysing Physical Education and Sport. Champaign, Illinois: Human Kinetics Books.

14- Diaz-Cueto, M., Hernandez-Alvarez, J. L., \& Castejon, F. J. (2010). Teaching Games for Understanding to In-Service Physical Education Teachers: Rewards and Barriers Regarding the Changing Model of Teaching Sport. Journal of Teaching in Physical Education, 29 (4), 378-398.

15- Dodds, P., Griffin, L. L., \& Placek, J. H. (2001). Chapter 2. A Selection Reviw of Literature on Devlopment of Learners' Domain-Specific Knowledge. Journal of Teaching in Physical Education, 20, 301-313.

16- Driscoll, M. (2005). Psychology of learning for instruction. Boston: MA: Allyn \& Bacon.

17- Ennis, C. D. (1999). Creating a Culturally Relevant Curriculum for Disengaged Girls. Sports, education and Society, 4 (1), 31-49.

18- Ertmer, P. A. \& Newby, T. J. (1993). Behaviorism, Cognitivism, Constructivism: Comparing Critical Features from an Instructional Design Perspective. Performance Improvement Quarterly, (6)4:50-72.

19- Fosnot, C.T. (Ed.) (2005). Constructivism: Theory, Perspectives, and Practice. New York: Columbia University Teachers College. 
20- French, K., Warner, P., Rink, J., Taylor, K., \& Hussey, K. (1996). The Effect of a 3-Week Unit of Tactical, Skill or Combined Tactical and Skill Instruction on Badminton Performance of Ninth-Grade Students. Journal for Teaching Physical Education, 15, 418-438.

21- French, K., Warner, P., Taylor, K., Hussey, K., \& Jones, J. (1996). The Effects of a 6-Week Unit of Tactical, Skill or Combined Tactical and Skill Instruction on Badminton Performance of Ninth-Grade Students. Journal of Teaching in Physical Education, 15, 439-463.

22- Gay, L. R., Mills, G. E., \& Airasian, P. (2006). Educational Research: Competencies for Analysis and Application (8th ed.). Columbus, Ohio: Pearson Prentice Hall.

23- Georgakis, S. (2006). From Drills to Game Sense Teacher Education: A 'Game for Outcome' Approach for Enhanced Understanding of Games. Asia Pacific Conference on Teaching Sport and Physical Education for Understanding (pp. 32-44). Sydney: The University of Sydney.

24- Glaserfeld, E. (1995). Radical Constructivism. London: Falmer.

25- Griffin, L.L., Brooker, R. \& Patton, K. (2005). Working towards legitimacy: two decades of teaching games for understanding. Physical Education and Sport Pedagogy, 10(3): 213-223.

26- Griffin, L., \& Patton, K. (2005). Two Decades of Teaching Games for Understanding: Looking at the Past, Present, and Future. In L. Griffin, \& J. Butler, Teaching Games for Understanding: Theory Research and Practice (pp. 1-17). USA: Human Kinetics.

27- Griffin, L., Dodds, P., Placek, J., \& Tremino, F. (2001). Middles School Students` Conception of Soccer: Thier Solution to Tactical Problems. Journal of Teaching in Physical Education, 20, 324-340.

28- Griffin, L., Mitchell, S. A., \& Oslin, J. L. (1995). Teaching Sports Concepts and Skills: A Tactical Games Approach. Champaign, IL: Human Hinetics.

29- Haneshi, K., Griffin, L., Siegel, D., \& Shelton, C. (2008). Effects of a Traditional Practice Approach and a Game Practice Approach on Game Performance, Skill Development and Intrinsic Motivation on Female Collegiate Soccer Players. 2008 Conference on Teaching Games for Understanding. Vancouver, Canada: University of British Columbia.

30- Harrison, J., Preece, L., Blakemore, C., Richards, R., Wilkinson, C., \& Fellingham, G. (1999). Effects of Two
Instructional Models - Skill Teaching and Mastery Learning - on Skill Developemnt, Knowldege, SelfEfficiacy, and Game Play in Volleyball. Journal of Teaching in Physical Education, 19, 34-57.

31- Harvey, S. (2003). Teaching Games for Understanding: A Study of U19 College Soccer Players Improvement in Games Performance Using The Games Performance Assessment Instrument. Proceedings of The 2nd International Conference Teaching Sport and Physical Education for Understanding (pp. 11-14). Melbourne: Universtity of Melbourne.

32- Hopper, T. (1998). Teaching Games Centred ApproachUsing Progressive Principles of Play. Canadian Association for Health, Physical Education, Recreation and Dance, 64(3): 3-7.

33- Hubball, H., Lambert, J., \& Hayes, S. (2007). Theory to Practice: Using the Games for Understanding Approach in the Teaching of Invasion Games. Physical \& Health Education Journal, 73 (3), 14-20.

34- Juniu, S. (2006). Use of Technology for Constructivist Learning in a Performance Assesment Class. Measurement in Physical Education and Exercise Science, 10(1), 67-79.

35- Kelly, A. (2003). Decision Making Using Game Theory: An Introduction for Managers. Cambridge: Cambridge University Press.

36- Kirk, D., Brooker, R., \& Braiuka, S. (2000). Teaching Games for Underatnding: a situated Perspective on Student Learning. American Educational Research Association Annual Meeting. New Orleans.

37- Light, R. (2003). A Snap Shot of Pre-Service and Beginning Teachers' Experiances of Implementing TGfU. 2nd International Conference: Teaching Sport and Physical Education for Understanding (pp. 44-52). Melbourne: University of Melbourne, Australia.

38- MacPhail, A., Kirk, D., \& Griffin, L. (2008). Throwing and Catching as Relational Skills in Game play: Situated Learning in a Modified Game Unit. Journal of Teaching Physical Education , 27, 100-115.

39- Mandigo, J., Butler, J., \& Hopper, T. (2007). What is Teaching Games for Understanding? A Canadian Perspective. Physical \& Health Education Journal, 73 (2), 14-20.

40- Mitchell, S. (2005). Teaching and Learning Games at the Elementary Level. In L. Griffin, \& J. Butler, Teaching Games for Understanding: Theory, Research and Practice (pp. 55-69). USA: Human Kinetics. 
41- Mitchell, S., Oslin, J., \& Griffin, L. (2006). Teaching Sport Concepts and Skills: A Tactical Games Approach (2 ed.). USA: Human Kinetics.

42- MOESD. (2008). Three-Year Junior Secondary Schools Syllabus: Physical Education. Gaborone: Ministry of Education and Skills Development, Goverment Printers.

43- Mosston, M., \& Ashworth, S. (1994). Teaching Physical Education (4 ed.). USA: Macmillan College Publishing Company.

44- Nevett, M., Rovegno, I., \& Babiarz, M. (2001). Fourth-Grade Children's Knowledge of Cutting, Passing and Tactics in Invasion Games after a 12-Lesson Unit of Instruction. Journal of Teaching in Physical Education, 20, 389-401.

45- Nevett, M., Rovegno, I., Babiarz, M., \& McCaughtry, N. (2001). Changes in Basic Tactics and Motor Skills in an Invasion-Type Game After a 12-Lesson Unit of Instruction. Journal of Teaching in Physical Education, 20, 352-369.

46- Oslin, J. (2005). The Role of Assessment in Teaching Games for Understanding. In L. Griffin, \& J. Butler, Teaching Games for Understanding: Theory, Research and Practice (pp. 125-135). USA: Human Kinetics.

47- Oslin, J., Mitchell, S., \& Griffin, L. (1998). The Game Performance Assessment Instrument (GPAI): Development and Preliminary Validation. Journal of Teaching In Physical Education, 19, 231-243.

48- Piaget, J. (1995). Sociological studies. London: Routledge.

49- Richard, J., \& Williams, N. (2005). Emphasizing Student Engagement in the Construction of Game Performance. In L. Griffin, \& J.
50- Butler, Teaching Games for Understanding: Theory, Research and Practice (pp. 19-32). USA: Human Kinetics.

51- Rink, J. (2002). Teaching Physical Education for Learning (4th ed.). New York: McGraw-Hill Higher Education.

52- Rossi, T., Fry, J. M., McNeill, M., \& Tan, C. W. (2007). The Games Cocept Approach (GCA) as a Mandated Practice: Views of Singaporean Teachers. Sports, Education and Society, 12 (1), 93-111.

53- Schunk, D. H. (2014). Learning Theories: An Educational Perspective. Essex: Pearson Education Limited.

54- Rovegno, I., Nevett, M., Brock, S., \& Babiarz, M. (2001). Teaching and Learning Basic Invasion-Game Tactics in 4th Grade: A descriptive Study from Situated and Constraints Theoretical Perspectives. Journal of Teaching in Physical Education, 20, 370-388.

55- Turner, A., \& Martinek, T. J. (1992). A Comparative Analysis of Two Teaching Models for Teaching Games (Technique Approach and Game-Centred (Tactical Focus) Approach). International Journal of Physical Education, 29, 131-152.

56- Werner, P., Thorpe, R., \& Bunker, D. (1996). Teaching Games for Understanding:Evolution of a Model. Journal of Physical Education, Recreation and Dance, 67 (1), 28-33.

57- Schunk, D. H. (2014). Learning Theories: An Educational Perspective. Essex: Pearson Education Limited.

58- Whitehead, S., \& Biddle, S. (2013). Adolescent girls' perceptions of physical activity: A focus group study. Education \& Educational Research, 19, 271-285. 